\title{
A TaqMan real-time PCR assay for the detection and quantitation of Plasmodium knowlesi
}

\author{
Paul CS Divis ${ }^{1}$, Sandra E Shokoples², Balbir Singh ${ }^{1 *}$, Stephanie K Yanow ${ }^{2,3}$
}

\begin{abstract}
Background: The misdiagnosis of Plasmodium knowlesi by microscopy has prompted a re-evaluation of the geographic distribution, prevalence and pathogenesis of this species using molecular diagnostic tools. In this report, a specific probe for $P$. knowlesi, that can be used in a previously described TaqMan real-time PCR assay for detection of Plasmodium spp., and Plasmodium falciparum, Plasmodium vivax, Plasmodium malariae and Plasmodium ovale, was designed and validated against clinical samples.

Methods: A hydrolysis probe for a real-time PCR assay was designed to recognize a specific DNA sequence within the $P$. knowlesi small subunit ribosomal RNA gene. The sensitivity, linearity and specificity of the assay were determined using plasmids containing $P$. knowlesi DNA and genomic DNA of $P$. falciparum, $P$. knowlesi, $P$. malariae, $P$. ovale and $P$. vivax isolated from clinical samples. DNA samples of the simian malaria parasites Plasmodium cynomolgi and Plasmodium inui that can infect humans under experimental conditions were also examined together with human DNA samples.
\end{abstract}

Results: Analytical sensitivity of the $P$. knowlesi-specific assay was 10 copies/ $\mu \mathrm{L}$ and quantitation was linear over a range of $10-10^{6}$ copies. The sensitivity of the assay is equivalent to nested PCR and $P$. knowlesi DNA was detected from all 40 clinical $P$. knowlesi specimens, including one from a patient with a parasitaemia of three parasites/ $\mu \mathrm{L}$ of blood. No cross-reactivity was observed with 67 Plasmodium DNA samples (31 P. falciparum, 23 P. vivax, six P. ovale, three $P$. malariae, one P. malariae/P. ovale, one P. falciparum/P. malariae, one P. inui and one P. cynomolgi) and four samples of human DNA.

Conclusions: This test demonstrated excellent sensitivity and specificity, and adds $P$. knowlesi to the repertoire of Plasmodium targets for the clinical diagnosis of malaria by real-time PCR assays. Furthermore, quantitation of DNA copy number provides a useful advantage over other molecular assays to investigate the correlation between levels of infection and the spectrum of disease.

\section{Background}

The sensitivity and specificity of a diagnostic test define the extent to which a pathogen can be effectively identified in a patient specimen. For malaria, the examination of thin and thick blood smears by microscopy has been the gold standard diagnostic method for over a century. This test is simple to perform, requires only a microscope and has a sensitivity of 50 parasites/ $\mu \mathrm{L}$ [1]. The parasitaemia can be quantified and the species of Plasmodium identified based on parasite morphology. When read by an experienced microscopist, the four major species of human malaria (Plasmodium falciparum,

\footnotetext{
*Correspondence: bskhaira55@gmail.com

${ }^{1}$ Malaria Research Centre, University Malaysia Sarawak, Sarawak, Malaysia Full list of author information is available at the end of the article
}

Plasmodium vivax, Plasmodium ovale and Plasmodium malariae) can usually be discriminated.

However, a major pitfall of microscopy was recently identified in the failure of this method to distinguish between the benign P. malariae species and the potentially lethal primate species Plasmodium knowlesi [2]. Zoonotic transmission of $P$. knowlesi from monkeys to humans was previously only observed in sporadic cases $[3,4]$ and by blood passage from monkeys to humans in laboratory controlled experiments [5-7] but was not routinely detected by microscopic analysis of patient specimens due to morphological similarities between $P$. knowlesi and P. malariae [8]. As such, P. knowlesi was not recognized as a cause of malaria in human populations, until recently. Using molecular diagnostic tools, 
including DNA sequencing and newly-developed $P$. knowlesi-specific PCR primers, Singh et al [2] examined blood samples from 208 malaria patients in the Kapit division of Malaysian Borneo, and found that none of the cases identified as $P$. malariae by microscopy were confirmed by PCR and 120 (58\%) were identified as P. knowlesi by PCR. These findings initiated a number of research studies into the epidemiological, clinical, ecological, and parasitological factors that determine the distribution and course of $P$. knowlesi infection. It is now recognized that human $P$. knowlesi malaria occurs in many countries in SouthEast Asia, causing locally-acquired malaria and infections in travelers returning from these regions [9-17]. Of significant concern, approximately 1 in 10 P. knowlesi infections lead to severe malaria and seven deaths have been reported from this species [18-20]. Plasmodium knowlesi has a 24-hour erythrocytic cycle, which is the shortest among the five species of Plasmodium causing human malaria, and therefore correct identification and rapid treatment are essential, particularly when the parasitaemia is high.

Given the potential for misdiagnosis of $P$. knowlesi by microscopy, alternative diagnostic tests must be employed to confirm this infection. Rapid diagnostic tests from two manufacturers have been evaluated for detection of $P$. knowlesi antigens. Cross-reactivity was observed with both $P$. falciparum and $P$. vivax antigens, precluding the use of these tests for rapid diagnosis [21]. Molecular diagnostics for detection of P. knowlesi include nested PCR and/or sequencing [2,22], LAMP [23], and real-time PCR [24]. In clinical diagnostic and reference laboratories, particularly those in developed countries, real-time PCR is the method of choice by providing superior sensitivity, rapid results and low risk of false positives. It is also far less laborious than nested PCR, enabling high throughput screening of patient samples. A number of real-time PCR assays have been developed for malaria diagnosis but these can only detect $P$. falciparum, $P$. vivax, $P$. malariae and $P$. ovale [25-31]. Only one assay has been reported for detection of P. knowlesi by real-time PCR [24]. However, the validation of this assay was limited to 2 reference DNA samples from infections in monkeys and no human clinical samples were tested. In the current report, a realtime PCR assay for P. knowlesi was developed and validated with clinical samples from 40 patients infected with P. knowlesi. The P. knowlesi assay developed uses the same reaction conditions of the real-time PCR assay described by Rougemount et al that screens for Plasmodium and identifies $P$. falciparum, $P$. vivax, P. malariae and $P$. ovale using species-specific probes [30].

\section{Methods}

\section{Samples}

Whole blood samples were collected from patients admitted with malaria to Kapit Hospital, Sarawak from July 2006 to February 2008 for a study aimed at determining the clinical and laboratory features of knowlesi malaria [20]. Blood samples were transported in liquid nitrogen to the Malaria Research Centre, University Malaysia Sarawak and stored in the $-80^{\circ} \mathrm{C}$ freezer. Parasitaemia was determined by examination of thick blood films by two experienced microscopists from the Malaria Research Centre, University Malaysia Sarawak and the Sarawak Health Department. The parasitaemia was estimated by counting the number of parasites per 500 white blood cells and then calculating the parasite counts from the total number of white blood cells per $\mu \mathrm{L}$ blood for each patient. The mean of the two parasitaemia for each sample was used in the data analysis. Forty patient samples with single $P$. knowlesi infections were randomly selected for this study [20]. Of these, 26 (65\%) had a parasitaemia below 500 parasites per $\mu \mathrm{L}$ blood and the rest ranged from 500 to 28,000 parasites per $\mu \mathrm{L}$ blood. Genomic DNA of P. falciparum (2 samples), $P$. vivax (4 samples), $P$. ovale (1 sample) and $P$. malariae (1 sample) were obtained from patients at Kapit Hospital. Plasmodium species in all patient samples were identified and confirmed by nested PCR assays [2]. The collection and testing of blood samples was approved by the Medical Research and Ethics Committee of the Malaysian Ministry of Health. Genomic DNA samples of Plasmodium cynomolgi and Plasmodium inui were obtained from the Biomedical Primate Research Centre, Rijswijk, the Netherlands. To determine the specificity of the P. knowlesi probe, an additional 57 samples (29 P. falciparum, $19 P$. vivax, five $P$. ovale, two $P$. malariae, one $P$. malariae/P. ovale and one $P$. falciparum/P. malariae) from the Provincial Laboratory for Public Health in Canada were tested from patients with acute malaria using the ABI 7500 platform. These samples were tested with approval from the Health Research Ethics Board of the University of Alberta.

\section{Plasmid DNA}

Part of the 18S rRNA gene of P. knowlesi KH33 (accession number AY327549) was cloned into $\mathrm{pCR}^{\circledR}$-Blunt vector (Invitrogen, USA) and verified by DNA sequencing. The concentration of plasmid DNA was determined by spectrophotometer for the calculation of the DNA copy number. For standard curve analysis in realtime PCR assays, the plasmid was diluted 10-fold in nuclease free water from $10^{6}$ copies to 1 copy per $\mu \mathrm{L}$. Threshold cycle $(\mathrm{C} t)$ values in real-time PCR assays 
were determined by the optimum standard curve produced by the dilutions of plasmid DNA.

\section{DNA extraction}

Whole blood samples were equilibrated at room temperature and $200 \mu \mathrm{L}$ of blood was used for DNA extraction. Genomic DNA was extracted according to the spin-column method using the QIAamp DNA Blood Mini Kit, as per the manufacturer's instructions (Qiagen, Germany) and eluted in a total volume of $200 \mu \mathrm{L}$ for each sample.

\section{Nested PCR}

The identification of Plasmodium species was performed by nested PCR as described previously [2]. For the first round of amplification, part of the $18 \mathrm{~S}$ rRNA gene was amplified using primers rPLU1 and rPLU5, which generates an amplicon of approximately $1650 \mathrm{bp}$ in length. The determination of Plasmodium species was carried out in the second nested amplification reaction for the identification of $P$. falciparum (primers rFAL1, rFAL2), $P$. vivax (rVIV1, rVIV2), P. ovale (rOVA1, rOVA4), P. malariae (rMAL1, rMAL2) and P. knowlesi (Pmk8, Pmkr9).

\section{Real-time PCR}

Real-time PCR was performed using TaqMan chemistry and hydrolysis probes. Two separate reactions were performed: 1) a screening reaction for the detection of all Plasmodium species, and 2) a specific reaction for the detection of $P$. knowlesi. Both reactions use the same primers (Plasmo 1 and 2), but distinct probes (Plasprobe and $\mathrm{Pk}$ probe), were utilised for screening and $P$. knowlesi identification, respectively. DNA sequences for the primers Plasmo 1 and 2 and the Plasmodium screening probe, Plasprobe, were reported previously [30]. The sequence of the probe specific for $P$. knowlesi, Pk probe, is the following: 5'-CTCTCCGGAGATTAGAACTCTTAGATTGCT-3'. Both Plasprobe and Pk probe were labelled with the fluorophore FAM on the 5' end with a black hole quencher BHQ-1 on the 3' end. Primers were synthesized by Integrated DNA Technologies (Iowa, USA) and probes by Biosearch Technologies, Inc. (Novato, CA, USA). The real-time PCR reaction consisted of $200 \mathrm{nM}$ of each primer, $80 \mathrm{nM}$ of probe, 12.5 $\mu \mathrm{L}$ TaqMan Universal Master Mix (Applied Biosystems, USA), and $5 \mu \mathrm{L}$ of DNA in a $25 \mu \mathrm{L}$ volume. Reactions were performed on the Mastercycler ${ }^{\circledast}$ ep realplex platform (Eppendorf, Germany) at the University Malaysia Sarawak, and on the ABI 7500 platform (Applied Biosystems, USA) at the Provincial Laboratory for Public Health in Canada, with the following cycling conditions: $50^{\circ} \mathrm{C}$ for $2 \mathrm{~min}$, initial denaturation at $95^{\circ} \mathrm{C}$ for $10 \mathrm{~min}$, and 45 cycles of $95^{\circ} \mathrm{C}$ for $15 \mathrm{sec}$ and $60^{\circ} \mathrm{C}$ for $1 \mathrm{~min}$.
Fluorescence data was collected during the annealing/ extension step at $60^{\circ} \mathrm{C}$. Cycle threshold $(\mathrm{C} t)$ values were analysed either by setting the threshold 10 times the standard deviation above the noise of baseline or adjusting the standard curve to optimum. The baseline was determined manually between cycles 3 and 15 .

\section{Statistical analyses}

Data were analysed using SPSS software, version 17.0. The strengths of the linear relationship between logarithms of mean parasitaemia and $\mathrm{C} t$ values for each probe were measured using the Pearson correlation coefficient. In this study, a negative correlation between parasitaemia and the $C t$ values due to the influence of parasite DNA copy numbers was hypothesized.

\section{Results \\ Assay design}

A real-time PCR assay for P. knowlesi was developed that is complementary to the Plasmodium screening assay published by Rougemont et al for P. falciparum, P. vivax, $P$. ovale and P. malariae [30]. Their assay enables rapid screening of patient specimens for Plasmodium and has been implemented within clinical diagnostic laboratories for confirmation of the species of Plasmodium [32,33]. The assay uses primers that bind to DNA sequences within the $18 \mathrm{~S}$ rRNA gene that are highly conserved across Plasmodium species. Detection with the TaqMan hydrolysis probe, Plasprobe, recognizes all species of Plasmodium that infect humans, including P. knowlesi $[30,33]$. In addition to the Plasmodium screening assay, the same primers can be used with species-specific probes that bind to a variable region within the target sequence. A $P$. knowlesi-specific probe was designed in the current study, called $\mathrm{Pk}$ probe, to bind specifically to a 30 base pair sequence within this variable region. Of the other human Plasmodium species, $P$. vivax shares the most homology with this sequence, however only $23 / 30$ bases are predicted to bind the Pk probe. Two primate species, $P$. cynomolgi and $P$. inui, share $26 / 30$ and $25 / 30$ sequence matches, respectively, and were therefore included in subsequent experiments to determine the specificity of the probe. A BLAST search using the Pk probe sequence did not identify any potential cross-reactivity with other pathogens or human DNA.

\section{Analytical validation of the $P$. knowlesi assay}

To determine the analytical sensitivity of the assay, the limit of detection was identified using a plasmid containing part of the $18 \mathrm{~S}$ rRNA gene from P. knowlesi. Ten-fold serial dilutions of this plasmid were prepared and served as the template in both the Plasprobe and $\mathrm{Pk}$ probe real-time PCR assays (Table 1). Based on the 
Table 1 Detection of $P$. knowlesi target gene in plasmid KH33 and genomic DNA

\begin{tabular}{|c|c|c|c|}
\hline Template & Concentration & $\begin{array}{l}\text { Plasprobe } \\
\text { Ct* }\end{array}$ & $\begin{array}{c}\text { Pk probe } \\
\mathrm{Ct}^{*}\end{array}$ \\
\hline \multirow[t]{7}{*}{ Plasmid (copies/ML) } & $1 \times 10^{6}$ & 23.3 & 20.5 \\
\hline & $1 \times 10^{5}$ & 26.7 & 23.6 \\
\hline & $1 \times 10^{4}$ & 30.3 & 27.7 \\
\hline & $1 \times 10^{3}$ & 34.1 & 31.0 \\
\hline & $1 \times 10^{2}$ & 37.6 & 34.4 \\
\hline & 10 & 40.3 & 37.5 \\
\hline & 1 & $\mathrm{ND} \neq$ & ND $\neq$ \\
\hline \multirow{7}{*}{$\begin{array}{l}\text { gDNAt(parasites/ } \mu \mathrm{L} \\
\text { blood) }\end{array}$} & 4480 & 26.7 & 25.6 \\
\hline & 480 & 28.5 & 27.4 \\
\hline & 48 & 32.2 & 31.1 \\
\hline & 4.8 & 35.8 & 34.7 \\
\hline & 0.48 & 40.2 & 38.8 \\
\hline & 0.048 & 42.4 & 39.5 \\
\hline & 0.0048 & ND $\ddagger$ & NDł \\
\hline
\end{tabular}

*Cycle threshold.

tGenomic DNA extracted from a clinical sample with single $P$. knowlesi infection.

$\mp N D$, not detected.

cycle threshold $(\mathrm{C} t)$ values, the Pk probe was more sensitive in detecting the target DNA sequence compared with the Plasprobe. This was observed in all dilutions tested. Despite this, the limit of detection was 10 copies of template per PCR reaction for both real-time assays and the efficiencies of the two PCR reactions were very similar (94\% for Plasprobe and 95\% for Pk probe). Both assays were linear between 10 and $10^{6}$ copies of template DNA.

The dynamic range of the assay was determined using serial dilutions of genomic DNA extracted from a patient sample infected with $P$. knowlesi (Table 1). As observed with the plasmid DNA, the Pk probe reaction had lower $\mathrm{C} t$ values, yet the overall sensitivity of the two assays was similar. Both real-time PCR assays detected $P$. knowlesi template over a dynamic range of 5 $\log$ dilutions.

\section{Specificity for $P$. knowlesi}

Plasmodium knowlesi has been largely overlooked as a human pathogen because it was identified mainly as P. malariae in blood films by microscopy. However, nested PCR revealed the widespread distribution of this parasite in human populations based on its ability to distinguish genetic variations between this species and other human malarias [2]. To determine the specificity of the $\mathrm{Pk}$ probe, a number of genomic DNA templates extracted from patients infected with other species of Plasmodium (Table 2) were tested. No cross-reactivity was observed for DNA samples from patients with $P$. vivax, P. falciparum,
P. malariae and P. ovale infections. Similar negative results were obtained with the Pk probe when 57 clinical samples from malaria patients were examined at the Provincial Laboratory for Public Health, Edmonton, Canada with the ABI 7500 platform. Furthermore, genomic DNA from two other primate species of Plasmodium, P. cyno$m o l g i$ and $P$. inui, that have the potential to cause zoonoses [34] were examined. Both of these species were detected using the Plasprobe, but neither was detected with the Pk probe (Table 2).

\section{Validation with clinical samples from patients infected with P. knowlesi}

To evaluate the accuracy of the real-time PCR assay, 40 blood samples from patients infected with $P$. knowlesi were examined. Samples were tested alongside gDNA extracted from patients infected with other species of Plasmodium (described above) and five uninfected samples as negative controls. For all samples, nested PCR served as the gold standard test. The panel was tested blind. All P. knowlesi samples were positive with both the Plasprobe and Pk probe by real-time PCR, including a sample with a parasitaemia as low as 3 parasites $/ \mu \mathrm{L}$ (Figure 1). As observed with plasmid DNA, the $C t$ values were lower for the $\mathrm{Pk}$ probe than the Plasprobe, but the overall sensitivity was $100 \%$ for both assays. Quantitation of the template copy number by real-time PCR demonstrated increased concentrations of parasite DNA with higher parasitaemic infections. There was a significant negative correlation between $\mathrm{C} t$ values and parasitaemia ( $\mathrm{p}<0.01$, Pearson correlation) for both the Plasprobe (Figure 1A) and the Pk probe (Figure 1B). Quantitative analysis of parasite DNA from clinical samples had a detection limit of 33 DNA copies/ $\mu \mathrm{L}$, corresponding to fewer than 6 parasites.

\section{Discussion}

In this report, the validation of a real-time PCR assay with a specific probe designed to detect $P$. knowlesi is described. The analytical sensitivity of the test is 10 copies per PCR; given the multicopy nature of the rRNA gene in Plasmodium $[35,36]$, this corresponds to approximately 1-2 parasite genomes. This sensitivity was corroborated with clinical samples that were detected by real-time PCR, even at a parasitaemia of 3 parasites $/ \mu \mathrm{L}$ of blood.

The assay also demonstrated excellent specificity for P. knowlesi. No cross-reactivity was observed with other Plasmodium species, including two closely related primate species $P$. cynomolgi and $P$. inui. The specificity is of particular importance given the historical misdiagnosis of $P$. knowlesi by microscopy. Only with the availability of molecular methods can the prevalence of this species be confirmed in human populations. However, molecular techniques can also be subject to specificity 
Table 2 Assay specificity for P. knowlesi

\begin{tabular}{cccc}
\hline Sample Code & Identification by nested PCR assay & Plasprobe $\mathbf{C t}^{*}$ & Pk probe $\mathbf{C t}^{*}$ \\
\hline MISC23 & P. vivax & 31.2 & $\mathrm{ND}+$ \\
CDK123 & P. vivax & 30.7 & $\mathrm{ND}+$ \\
CDK118 & P. vivax & 27.6 & $\mathrm{ND}+$ \\
SKS358 & P. vivax & 26.7 & $\mathrm{ND}+$ \\
KH116 & P. falciparum & 25.1 & $\mathrm{ND}+$ \\
CDK135 & P. falciparum & 26.7 & $\mathrm{ND}+$ \\
CDK67 & P. malariae & 37.0 & $\mathrm{ND}+$ \\
KH352 & P. ovale & 26.5 & $\mathrm{ND}+$ \\
P. cynomolgi & Plasmodium-positive & 15.0 & $\mathrm{ND}+$ \\
P. inui & Plasmodium-positive & 13.0 & $\mathrm{ND}+$ \\
\end{tabular}

${ }^{*}$ Cycle threshold.

†ND, not detected.

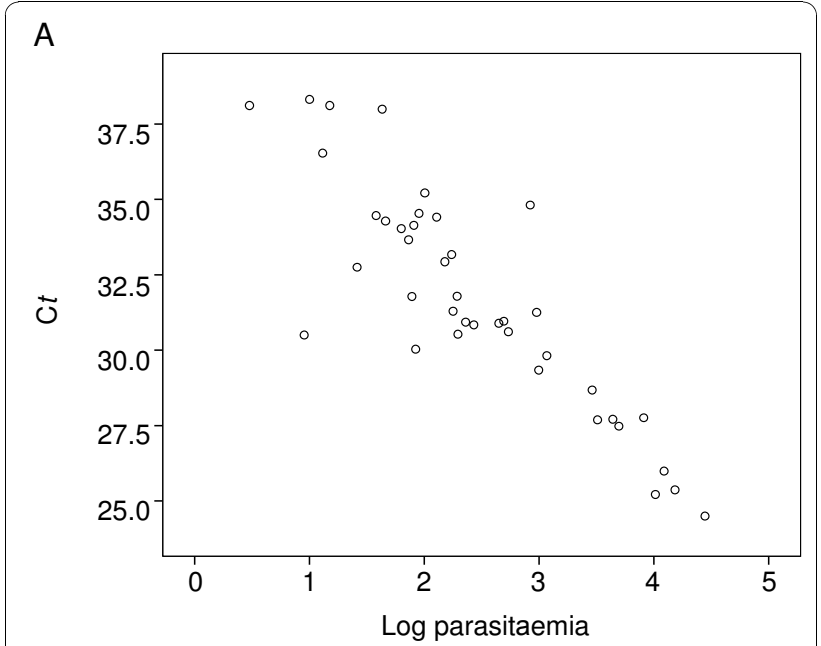

B

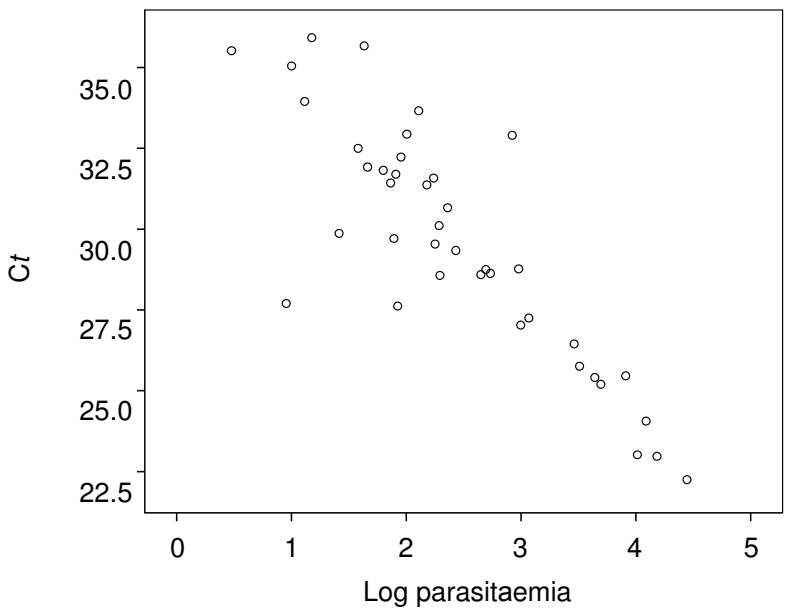

Figure 1 Correlation between $\mathbf{C t}$ value and parasitaemia. Log parasitaemia values (parasites/ $\mu \mathrm{L}$ blood) were plotted against $\mathrm{Ct}$ values from the Plasprobe (A) and Pk probe (B) PCR reactions, for 40 blood samples infected with $P$. knowlesi. issues. In recent studies, concerns were raised that primers used to detect $P$. knowlesi by nested PCR spuriously amplify a proportion of $P$. vivax genomic DNA samples, resulting in false positive results for $P$. knowlesi $[22,37]$. In the real-time PCR assay described, one set of primers amplifies all five species of Plasmodium but specificity is achieved through the design of the hydrolysis probe. This was supported experimentally, as no cross-reactivity of the Pk probe was observed with DNA from 65 clinical specimens infected with Plasmodium species other than $P$. knowlesi, including 23 P. vivax DNA samples. However, competition for the conserved primers may compromise the sensitivity of detection for mixed infections with $P$. knowlesi.

The $P$. knowlesi assay developed uses the same reaction conditions of a previously published real-time PCR assay by Rougemount et al that screens for all human species of Plasmodium and identifies the species using specific probes $[30,33]$. The real-time assay by Rougemount et al has been successfully implemented in two provincial public health laboratories in Canada using the ABI 7500 and 7900 platforms [32,33]. In the current study, validation for the Plasprobe and Pk probe reactions was performed on the Eppendorf platform with no loss in sensitivity compared with the ABI systems. The versatility of this test for different real-time PCR platforms is an advantage for clinical diagnostic laboratories implementing this methodology for malaria species confirmation. Other general advantages of real-time PCR include the low risk of contamination and rapid, automated processing, enabling high throughput diagnostic testing. For malaria, this test can be readily employed to evaluate patient samples that are positive for Plasmodium but unidentified at the species level. Samples can also be tested with the $\mathrm{Pk}$ probe alongside the multiplex assay for the other four species to investigate potential mixed infections [33]. Furthermore, quantitation of $P$. knowlesi DNA copy number by real-time PCR 
provides a measure of the level of infection, analogous to the parasitaemia calculated from a blood smear. Quantitative analysis of parasitaemia by real-time PCR can be correlated with the clinical presentation of disease to better understand the pathogenesis of this species in the human host.

\section{Conclusions}

This study reports the analytical and clinical validation of a new real-time PCR assay for P. knowlesi based on TaqMan technology. The assay demonstrated excellent sensitivity, linearity and specificity with plasmid DNA and genomic DNA isolated from patients infected with P. knowlesi. This diagnostic tool can be useful for prospective and retrospective analysis of samples for surveillance and epidemiological studies. The impact of the under-diagnosis of $P$. knowlesi by microscopy is of global concern and rapid screening tools that can process archived samples will be invaluable to reassess the geographical distribution of this species.

\section{Acknowledgements}

We thank Dr. Alan Thomas of the Biomedical Primate Research Centre, Rijswijk, the Netherlands for providing the genomic DNA samples of $P$. cynomolgi and $P$. inui.

This study was funded by a grant from Universiti Malaysia Sarawak (No 01/ (\$49/714/2009[30]) and research support from Alberta Health Services.

\section{Author details \\ ${ }^{1}$ Malaria Research Centre, University Malaysia Sarawak, Sarawak, Malaysia. ${ }^{2}$ Provincial Laboratory for Public Health, Edmonton, Canada. ${ }^{3}$ School of Public Health, University of Alberta, Edmonton, Canada.}

\section{Authors' contributions}

PCSD and SES were involved in the laboratory work (blood processing, nested PCR and real-time PCR testing), data analysis and revision of the manuscript. BS and SKY designed the experiments, provided supervision, analysis and technical assistance, and wrote the paper. All authors read and approved the final manuscript.

\section{Competing interests}

The authors declare that they have no competing interests.

Received: 2 September 2010 Accepted: 30 November 2010 Published: 30 November 2010

\section{References}

1. Moody A: Rapid diagnostic tests for malaria parasites. Clin Microbiol Rev 2002, 15:66-78.

2. Singh B, Kim SL, Matusop A, Radhakrishnan A, Shamsul SS, Cox-Singh J, Thomas A, Conway DJ: A large focus of naturally acquired Plasmodium knowlesi infections in human beings. Lancet 2004, 363:1017-1024.

3. Chin W, Contacos PG, Coatney GR, Kimball HR: A naturally acquired quotidian-type malaria in man transferable to monkeys. Science 1965, 149:865.

4. Fong YL, Cadigan FC, Coatney GR: A presumptive case of naturally occurring Plasmodium knowlesi malaria in man in Malaysia. Trans $R$ Soc Trop Med Hyg 1971, 65:839-840.

5. Ciuca M, Tomescu P, Badenski G, Badenski A, lonescu P, Teriteanu M: Contribution à l'étude de la virulence du Plasmodium knowlesi chez I'homme. Caratères de la maladie et biologie du parasite. Arch Roumaine Path Experim Microbiol 1937, 10:5-28.
6. Garnham P: Malaria parasites and other haemosporidia Oxford: Blackwell Scientific Publications; 1966.

7. Knowles R, Das Gupta B: A study of monkey-malaria and its experimental transmission to man. Indian Medical Gazette 1932, 67:301-320.

8. Lee KS, Cox-Singh J, Singh B: Morphological features and differential counts of Plasmodium knowlesi parasites in naturally acquired human infections. Malar J 2009, 8:73.

9. Bronner U, Divis $P C$, Färnert A, Singh B: Swedish traveller with Plasmodium knowlesi malaria after visiting Malaysian Borneo. Malar J 2009, 8:15.

10. Ennis J, Teal A, Habura A, Madison-Antenucci S, Keithly J, Arguin P, Barnwell J, Collins W, Mali S, Slutsker L, Dasilva A, Hwang J: Simian malaria in a U.S. traveler-New York, 2008. MMWR Morb Mortal Wkly Rep 2009, 13:229-232.

11. Figtree $M$, Lee R, Bain L, Kennedy T, Mackertich S, Urban M, Cheng $Q$, Hudson BJ: Plasmodium knowlesi in Human, Indonesian Borneo. Emerg Infect Dis 2010, 16:672-674.

12. Jongwutiwes S, Putaporntip C, Iwasaki T, Sata T, Kanbara H: Naturally acquired Plasmodium knowlesi malaria in human, Thailand. Emerg Infect Dis 2004, 10:2211-2213.

13. Kantele A, Marti H, Felger I, Muller D, Jokiranta TS: Monkey malaria in a European traveler returning from Malaysia. Emerg Infect Dis 2008, 14:1434-1436.

14. Luchavez J, Espino F, Curameng P, Espina R, Bell D, Chiodini P, Nolder D, Sutherland C, Lee KS, Singh B: Human infections with Plasmodium knowlesi, the Philippines. Emerg Infect Dis 2008, 14:811-813.

15. Ng OT, Ooi EE, Lee CC, Lee PJ, Ng LC, Pei SW, Tu TM, Loh JP, Leo YS: Naturally acquired human Plasmodium knowlesi infection, Singapore. Emerg Infect Dis 2008, 14:814-816.

16. Van den Eede P, Vythilingam I, Ngo DT, Nguyen VH, Le XH, D'Alessandro U, Erhart A: Plasmodium knowlesi malaria in Vietnam: some clarifications. Malar I 2010, 9:20.

17. Vythilingam I, Noorazian YM, Huat TC, Jiram Al, Yusri YM, Azahari AH, Norparina I, Noorrain A, Lokmanhakim S: Plasmodium knowlesi in humans, macaques and mosquitoes in peninsular Malaysia. Parasit Vectors 2008, 1:26.

18. Cox-Singh J, Davis TM, Lee KS, Shamsul SS, Matusop A, Ratnam S, Rahman HA, Conway DJ, Singh B: Plasmodium knowlesi malaria in humans is widely distributed and potentially life threatening. Clin Infect Dis 2008, 46:165-171.

19. Cox-Singh J, Hiu J, Lucas SB, Divis PC, Zulkarnaen M, Chandran P, Wong KT, Adem P, Zaki SR, Singh B, Krishna S: Severe malaria - a case of fatal Plasmodium knowlesi infection with post-mortem findings: a case report. Malar J 2010, 9:10.

20. Daneshvar C, Davis TM, Cox-Singh J, Rafa'ee MZ, Zakaria SK, Divis PC, Singh B: Clinical and laboratory features of human Plasmodium knowlesi infection. Clin Infect Dis 2009, 49:852-860.

21. Kawai S, Hirai M, Haruki K, Tanabe K, Chigusa Y: Cross-reactivity in rapid diagnostic tests between human malaria and zoonotic simian malaria parasite Plasmodium knowlesi infections. Parasitol Int 2009, 58:300-302.

22. Imwong M, Tanomsing N, Pukrittayakamee S, Day NP, White NJ, Snounou G: Spurious amplification of a Plasmodium vivax small-subunit RNA gene by use of primers currently used to detect $P$. knowlesi. J Clin Microbiol 2009, 47:4173-4175.

23. Iseki H, Kawai S, Takahashi N, Hirai M, Tanabe K, Yokoyama N, Igarashi I: Evaluation of a Loop-Mediated Isothermal Amplification (LAMP) method as a diagnostic tool of zoonotic simian malaria parasite Plasmodium knowlesi infection. J Clin Microbiol 2010, 48:2509-2514.

24. Babady NE, Sloan LM, Rosenblatt JE, Pritt BS: Detection of Plasmodium knowlesi by real-time polymerase chain reaction. Am J Trop Med Hyg 2009, 81:516-518.

25. deMonbrison F, Angei C, Staal A, Kaiser K, Picot S: Simultaneous identification of the four human Plasmodium species and quantification of Plasmodium DNA load in human blood by real-time polymerase chain reaction. Trans $R$ Soc Trop Med Hyg 2003, 97:387-390.

26. Elsayed S, Plewes K, Church D, Chow B, Zhang K: Use of molecular beacon probes for real-time PCR detection of Plasmodium falciparum and other Plasmodium species in peripheral blood specimens. I Clin Microbiol 2006, 44:622-624.

27. Farcas GA, Zhong KJ, Mazzulli T, Kain KC: Evaluation of the RealArt Malaria LC real-time PCR assay for malaria diagnosis. J Clin Microbiol 2004, 42:636-638. 
28. Mangold KA, Manson RU, Koay ES, Stephens L, Regner M, Thomson RB Jr, Peterson LR, Kaul KL: Real-time PCR for detection and identification of Plasmodium spp. J Clin Microbiol 2005, 43:2435-2440.

29. Perandin F, Manca N, Calderaro A, Piccolo G, Galati L, Ricci L, Medici MC, Arcangeletti MC, Snounou G, Dettori G, Chezzi C: Development of a realtime PCR assay for detection of Plasmodium falciparum, Plasmodium vivax, and Plasmodium ovale for routine clinical diagnosis. I Clin Microbiol 2004, 42:1214-1219.

30. Rougemont M, Van SM, Sahli R, Hinrikson HP, Bille J, Jaton K: Detection of four Plasmodium species in blood from humans by $18 \mathrm{~S}$ rRNA gene subunit-based and species-specific real-time PCR assays. J Clin Microbiol 2004, 42:5636-5643.

31. Vo TK, Bigot P, Gazin P, Sinou V, De Pina JJ, Huynh DC, Fumoux F, Parzy D: Evaluation of a real-time PCR assay for malaria diagnosis in patients from Vietnam and in returned travellers. Trans R Soc Trop Med Hyg 2007 101:422-428.

32. Khairnar K, Martin D, Lau R, Ralevski F, Pillai DR: Multiplex real-time quantitative $\mathrm{PCR}$, microscopy and rapid diagnostic immunochromatographic tests for the detection of Plasmodium spp: performance, limit of detection analysis and quality assurance. Malar J 2009, 8:284.

33. Shokoples SE, Ndao M, Kowalewska-Grochowska K, Yanow SK: Multiplexed real-time PCR assay for discrimination of Plasmodium species with improved sensitivity for mixed infections. J Clin Microbiol 2009, 47:975-980,

34. Coatney GR, Collins WE, Warren MCW, Contacos PG: The Primate Malarias U. S Government Printing Office, Washington D.C; 1972.

35. Corredor V, Enea V: The small ribosomal subunit RNA isoforms in Plasmodium cynomolgi. Genetics 1994, 136:857-865.

36. Gardner MJ, Hall N, Fung E, White O, Berriman M, Hyman RW, Carlton JM, Pain A, Nelson KE, Bowman S, Paulsen IT, James K, Eisen JA, Rutherford K, Salzberg SL, Craig A, Kyes S, Chan MS, Nene V, Shallom SJ, Suh B, Peterson J, Angiuoli S, Pertea M, Allen J, Selengut J, Haft D, Mather MW, Vaidya AB, Martin DM, Fairlamb AH, Fraunholz MJ, Roos DS, Ralph SA, MCFadden Gl, Cummings LM, Subramanian GM, Mungall C, Venter JC, Carucci DJ, Hoffman SL, Newbold C, Davis RW, Fraser CM, Barrell B: Genome sequence of the human malaria parasite Plasmodium falciparum. Nature 2002, 419:498-511.

37. Sulistyaningsih $E$, Fitri LE, Loscher T, Berens-Riha N: Diagnostic difficulties with Plasmodium knowlesi infection in humans. Emerg Infect Dis 2010, 16:1033-1034.

doi:10.1186/1475-2875-9-344

Cite this article as: Divis et al:: A TaqMan real-time PCR assay for the detection and quantitation of Plasmodium knowlesi. Malaria Journal 2010 9:344.

\section{Submit your next manuscript to BioMed Central and take full advantage of:}

- Convenient online submission

- Thorough peer review

- No space constraints or color figure charges

- Immediate publication on acceptance

- Inclusion in PubMed, CAS, Scopus and Google Scholar

- Research which is freely available for redistribution

Submit your manuscript at www.biomedcentral.com/submit
Biomed Central 